reluctant to apply for help. In the less technical problems firms are not always ready to profit by the experience of others, and the report comments on the aircraft industry's neglect of statistical methods of quality control. Other recommendations for improving efficiency include the strengthening of design staffs by the appointment of draughtsmen with actual experience of production engineering, and arranging that design and development offices and planning departments are within the same premises and housed as close to each other as possible. More appointments similar to that of the technical advisor to the chief executive should be made, even if it involves the temporary withdrawal of men occupying important positions in the industry. In regard to the co-ordination of production with research and development the report notes that the importance of this requirement has lately received greater recognition, and strenuous efforts are made to this end through weekly meetings of the controller of research and development with the officers responsible for production. The advantages of collective consultations on the allocation of orders in important changes of programmes are stressed and also the necessity for close attention to the problem of reducing the loss of output caused by change-over from an old to a new type.

\section{Dr. Carl Voegtlin}

Dr. Cart Voegtuin has resigned from the directorship of the National Cancer Institute, U.S. Public Health Service. Dr. Voegtlin, who has been director of the Institute since its foundation in 1938, is sixtyfour years of age. He has recently been presented with a portrait of himself at a meeting of the U.S. National Cancer Advisory Council. Before taking over as director of the National Cancer Institute, Dr. Voegtlin had been chief of the Division of Pharmacology in the National Institute of Health. He went to that Division of the U.S. Public Health Service in 1913 from Johns Hopkins Medical School, where he had been associate professor of pharmacology. Born in Switzerland and educated in the Universities of Basel, Munich, Geneva and Frieberg, Dr. Voegtlin has had a distinguished career, and an international reputation for his researches in physiology, pharmacology and cancer.

\section{Summer School in Biology and Health}

Approximately 250 students attended the Summer School in Biology and Health of the Central Council for Health Education held during August 4-14 at the Chelsea Polytechnic, London. They represented a very wide variety of educational activity, including junior, senior and secondary school teachers, head teachers, training college lecturers, health visitors and nurses, educational administrators, teachers of physical education and domestic science, and representatives of commercial houses. This mixture of different categories was particularly valuable in discussion, since it enabled the various points of view to be expressed. These discussions, and particularly those on sex education, were most fruitful. During the School, students visited experimental stations, health centres and clinics, and there were demonstrations of biological experiments, health education pamphlets and teaching material. In addition, there was a display of text-books and shows of biological and health education films.
Among the lecturers at the School were Dr. Charles Hill, who gave the inaugural address on "Biology and Health", Prof. C. W. Valentine and Prof. Lancelot Hogben of Birmingham University, who spoke on "Early Childhood" and "Biology as a Social Science" respectively. Miss Enid Blyton described "Education Through Story Telling", Miss F. Brackenbury gave an address on "Practical Methods in Health Teaching", Prof. J. R. Marrack spoke on "Social Aspects of Nutrition", Mr. L. J. F. Brimble lectured on "Social Studies and World Citizenship", and Sir John Russell gave the final address, on "Agricultural Developments in the U.S.S.R." "The demand to attend the School was so great that many prospective students had to be turned away, and it is likely that next year more Schools will be held both in the North and in the South of England.

\section{Sociological Value of Family Meals}

FAMILY table talk plays a vital part in rearing children. During mealtime, the time when the whole family is likely to be together, children learn moral values, absorb family culture, and develop as individuals, according to Prof. J. H. S. Bossard, of the University of Pennsylvania (Amer. Sociol. Rev., June 1943). The dining-room is often the real social centre of the household, and the family is apt to be at its greatest ease at the dining table. The influence of conversation at this time is subtle and intangible, but the part which it plays in rearing children is most important.

Mary's place in the family group becomes most clearly defined and the family serves as her sounding. board during meal-time. Both in the responses given and withheld, the family carries great weight in the moulding of her personality. It is here that the individual members aid in enlarging each other's vocabulary, and "facility and quickness in expression constitute the price for admittance to the conversation", states Dr. Bossard. The family dining table is likened to a clearing house for information, news, and experiences. In some families, according to Prof. Bossard, meal-time serves as a forum, sometimes it substitutes for class-room instruction, and again it may be the one place where problems of importance to the entire family are thrashed out. A child's interests can be stimulated and directed during meals. If Mary has artistic, literary, or mechanical interests, family table talk can either increase or dampen the development of these interests.

\section{Almanacs and Health Education}

According to an editorial in the February issue of the Boletin de la Oficina Sanitaria Panamericana, almanacs have recently been revived as a means of health education. The Division of Malariology in the Argentine, for example, lately used this device in its anti-malarial campaign, and in Venezuela the Ministry of Public Health and Social Welfare published health calendars in 1940. The calendar reaches every social level, including peasants, schools, industrial groups and every public and private institution. A national calendar may include among other items notes on scientific advances of general interest, radio progress, museums, periodicals, ways of preparing food, vaccination, rules for maternal and infant hygiene, social security legislation and economic data. 